Submitted, accepted and published by:

International Journal of Greenhouse Gas Control 52 (2016) 120-129

\title{
Long-lasting Cu-based Oxygen Carrier Material for Industrial Scale in Chemical Looping Combustion
}

A. Cabello ${ }^{a}$, P. Gayán ${ }^{\text {a* }}$ A. Abad ${ }^{\text {a }, ~ L . ~ F . ~ d e ~ D i e g o ~ a ~, ~ F . ~ G a r c i ́ a-L a b i a n o ~}{ }^{a}$, M. T. Izquierdo ${ }^{a}$, A. Scullard $^{\mathrm{b}}, \mathrm{G}$. Williams ${ }^{\mathrm{b}}, \mathrm{J}$. Adánez ${ }^{\mathrm{a}}$

${ }^{\text {a } I n s t i t u t o ~ d e ~ C a r b o q u i ́ m i c a ~(I C B-C S I C), ~ D e p a r t m e n t ~ o f ~ E n e r g y ~ a n d ~ E n v i r o n m e n t, ~ M i g u e l ~}$ Luesma Castán 4, Saragossa 50018, Spain.

b Johnson Matthey, Technology Centre, Blounts Court, Sonning Common, Reading RG4 9NH, United Kingdom

* Corresponding author: Tel.: +34 976733 977; fax: +34 976733 318. E-mail address: pgayan@icb.csic.es (Pilar Gayán).

\begin{abstract}
One of the most important current objectives of the Chemical Looping Combustion (CLC) technology for gaseous fuels lies in scaling-up the aforementioned technology in the short term from $100 \mathrm{~kW}_{\text {th }}$ to $10 \mathrm{MW}_{\text {th }}$ scale. In order to meet this challenge, the commercial availability of suitable multi ton-scale oxygen carrier materials at competitive price is needed. In this work, a Cu-based oxygen carrier prepared by the impregnation method using a commercial alumina as support, referred as Cu14 $\gamma$ Al_Commercial, has been developed and evaluated in a $500 \mathrm{~W}_{\text {th }} \mathrm{CLC}$ pilot plant during the combustion of $\mathrm{CH}_{4}$ at two different
\end{abstract}


temperatures, i.e., $800{ }^{\circ} \mathrm{C}$ and $900{ }^{\circ} \mathrm{C}$. The outstanding results obtained in terms of both

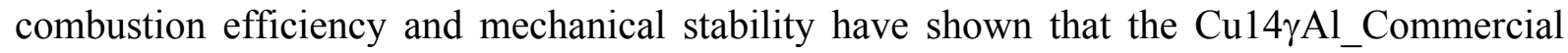
impregnated oxygen carrier can be selected to upscale CLC technology for gaseous fuels.

Keywords: $\mathrm{CO}_{2}$ capture; Chemical Looping Combustion; oxygen carrier; copper oxide; attrition.

\section{Introduction}

The application of Carbon Dioxide Capture and Storage (CCS) technologies to large fossil fuel power plants implies an increase of the cost of energy, since carbon dioxide $\left(\mathrm{CO}_{2}\right)$ capture is a highly energy intensive process. Regarding $\mathrm{CO}_{2}$ capture, there are three approaches, designated as first generation CCS technologies, that have undergone a great development during the last decades, and some of them are today available at commercial scale. These technologies are known as pre-combustion, post-combustion and oxy-fuel combustion. However, although these processes can greatly reduce $\mathrm{CO}_{2}$ emissions, they also result in a high energy penalty to perform the gas-separation steps involved. ${ }^{1}$

In recent years, significant efforts are underway to develop new $\mathrm{CO}_{2}$ capture technologies with the aim of reducing the costs associated with that process. Within these new technologies, Chemical Looping Combustion (CLC) has been suggested as one of the most promising technologies for $\mathrm{CO}_{2}$ capture in power generation because $\mathrm{CO}_{2}$ separation is inherent to the process, which explains its relatively lower cost. ${ }^{2}$ CLC is a combustion concept where air and fuel are never mixed. Thus, the $\mathrm{CO}_{2}$ generated is not diluted by the nitrogen $\left(\mathrm{N}_{2}\right)$ present in the air stream and, consequently, the corresponding gas-gas separation process is inherently avoided. The principle of CLC for gaseous fuels is shown in Fig. 1. Metal oxides $\left(\mathrm{M}_{\mathrm{x}} \mathrm{O}_{\mathrm{y}}\right)$ are used to selectively transport oxygen from the air reactor to 
the fuel reactor, which usually are two interconnected fluidized-bed reactors. Ideally, the fuel reactor exhaust stream only contains $\mathrm{CO}_{2}$ and $\mathrm{H}_{2} \mathrm{O}$ while the air reactor exhaust stream is oxygen-depleted air. This fact means that all the carbon present in the gaseous fuel can be captured as $\mathrm{CO}_{2}$, which is available in concentrated form after simple condensation of the steam. Furthermore, it must be highlighted that the total heat released from the CLC system is equal to the one obtained during direct combustion and, thus, the corresponding energy penalty is reduced to the $\mathrm{CO}_{2}$ compression and purification efforts which all capture processes have in common.

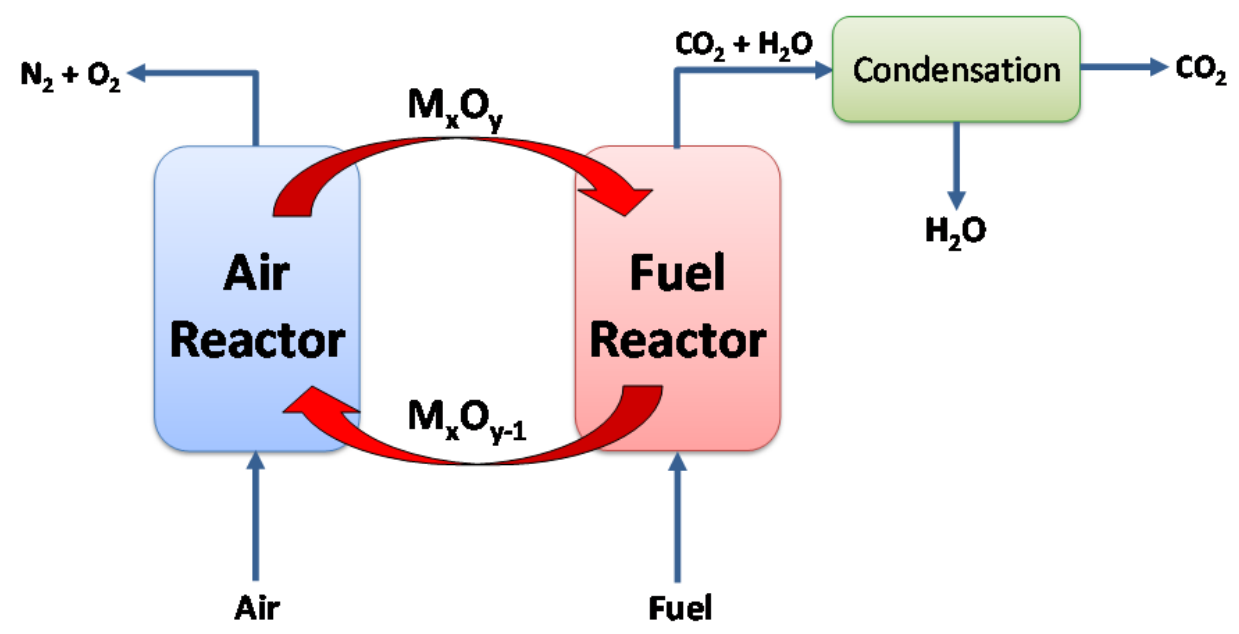

Fig. 1 General scheme of the CLC process for gaseous fuels.

An oxygen carrier, which is the core part of a CLC system, is usually composed of a metal oxide and an inert material in a particulate form. The main objectives of the former are to provide a high oxygen transport capacity and to facilitate a complete conversion of the fuel to $\mathrm{CO}_{2}$ and $\mathrm{H}_{2} \mathrm{O}$, whereas the inert material acts as support providing a high surface area for chemical reaction and increasing the mechanical strength and attrition resistance of the whole oxygen carrier. 
Up to now, CLC technology for gaseous fuels has been successfully demonstrated with more than 4000 hours of operational experience in continuous CLC plants up to $140 \mathrm{~kW}_{\text {th }}$ using more than 40 different oxygen carriers. ${ }^{3,4}$ The next challenge is to upscale this technology from $140 \mathrm{~kW}$ to $10 \mathrm{MW}$ since there is a promising niche application in on-field steam generation with CCS. In particular, CLC has the possibility to be applied to replace conventional $\mathrm{CO}_{2}$ capture systems in the oil and gas industry for heat and steam generation. Successful upscaling of this technology is highly dependent on the upscaling of two aspects in parallel, namely 1) upscaling of reactor system and 2) upscaling of oxygen carrier manufacture. Most efforts are being allocated to upscale the CLC system designs to the desired power of $10 \mathrm{MW}^{5}$

In respect of the development of materials, research must be focused on providing materials with high reactivity and attrition resistance. Usually, the attrition behaviour of an oxygen carrier is determined by long-time operation in a CLC unit. Then, the lifetime of the material can be estimated. Complementary methods for the analysis of the durability of oxygen carrier particles based on "customized attrition rigs" ${ }^{\prime-8}$ have been proposed in literature. Recently, Cabello et al. ${ }^{9}$ have proposed a methodology based on the ASTM D5757 standard test $^{10}$ to select oxygen carriers for CLC upscale related to attrition behaviour.

Generally, the preparation methods proposed for large-scale oxygen carrier production are spray drying and impregnation. ${ }^{3}$ Concerning spray drying, relevant results have been obtained with nickel- and manganese-based oxygen carriers. The oxygen carriers based on nickel oxide were the first ones in which it was thought to upscale the CLC process for gaseous fuels as they exhibited high reactivity and low attrition rate values. In particular, very high combustion efficiency values using $\mathrm{CH}_{4}$ as fuel as well as estimated particle lifetimes higher than 30000 hours were achieved with Ni-based oxygen carriers prepared by means of spray-drying. ${ }^{11}$ 
However, health and environmental issues aim to minimize the use of Ni-based oxygen carriers at industrial scale due to the high toxicity of this metal. Thus, research is currently focused on the development of oxygen carriers based on other metals such as $\mathrm{Fe}, \mathrm{Cu}$ and $\mathrm{Mn}$. With regard to spray dried Mn-based oxygen carriers, materials based on $\mathrm{CaMnO}_{3-\delta}$ perovskite present a very good performance for the CLC process with gaseous fuels in terms of reactivity and mechanical stability. ${ }^{6,12}$

The impregnation method consists in depositing a solution that contains the active metal on the support. This is an easy and well-established technique that is thoroughly used for the production of catalysts at multi-ton scale. Several impregnated oxygen carriers have exhibited a good performance in terms of high reactivity towards different gaseous fuels such as $\mathrm{CH}_{4}$, $\mathrm{CO}$ or $\mathrm{H}_{2}{ }^{4,13-20}$ and physicochemical stability in CLC pilot plants to burn gaseous fuels. ${ }^{21-36}$ For example, Ni-, $\mathrm{Fe}$ - and $\mathrm{Cu}$-based materials prepared by means of the impregnation method using alumina as support showed particle lifetime values of 10000, 1100 and 2500 hours, respectively. $^{21-23}$

Among the different metal oxides, copper oxide presents very suitable characteristics for the CLC process which make it one of the best candidates to be part of an oxygen carrier. ${ }^{3}$ It should be pointed out that the selection of the impregnation process as preparation method for $\mathrm{Cu}$-based oxygen carriers has allowed a satisfactory use of this type of materials in CLC units with gaseous fuels. A Cu-based oxygen carrier with 14.2 wt.\% $\mathrm{CuO}$ content, and prepared by dry impregnation using $\gamma-\mathrm{Al}_{2} \mathrm{O}_{3}$ as support, was evaluated during the combustion of $\mathrm{CH}_{4}$, syngas and light hydrocarbons in two CLC pilot plants of $500 \mathrm{~W}_{\text {th }}$ and $10 \mathrm{~kW}_{\text {th }}$ achieving a good performance in terms of combustion efficiency. ${ }^{22,30-33}$ Moreover, the particle lifetime inferred at $800{ }^{\circ} \mathrm{C}$ was 2500 hours, which is an adequate value that does not represent a limitation to the technology development in terms of the cost of the particles. ${ }^{37}$ Nevertheless, 
temperatures higher than $800^{\circ} \mathrm{C}$ had to be avoided in the fuel reactor in order to preserve the integrity of the particles. ${ }^{33}$

The remarkable results previously discussed were achieved with a $\mathrm{Cu}$-based oxygen carrier, designated as $\mathrm{Cu} 14 \gamma \mathrm{Al}$ ICB, prepared at lab-scale using alumina as support. The main drawback to upscale the production of this material is that it was developed using a support not available at multi-ton scale. Therefore, suitable oxygen carrier materials at multi ton-scale and competitive price will be required to meet the challenge of upscaling CLC technology.

The main goal of this work consists in developing an impregnated $\mathrm{Cu}$-based oxygen carrier with a commercial support prepared at industrial scale whose properties for the CLC process

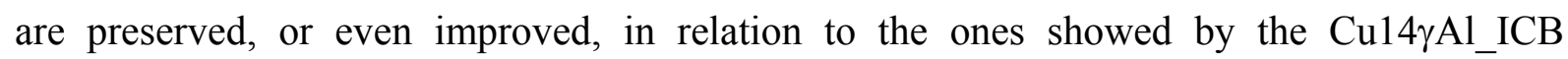
material. In this way, a commercial support based on $\gamma-\mathrm{Al}_{2} \mathrm{O}_{3}$ has been used to prepare the new impregnated Cu-based oxygen carrier, designated as Cu14 $\gamma \mathrm{Al}$ _Commercial, which has been evaluated in a continuous $500 \mathrm{~W}_{\text {th }}$ CLC pilot plant during $\mathrm{CH}_{4}$ combustion tests. The effect of the temperature and the oxygen carrier-to-fuel ratio $(\phi)$ on the combustion efficiency has been analysed. Moreover, the evolution of the main physicochemical properties of the oxygen carrier along the operation time has been studied, focusing the interest on the attrition behaviour as well as on chemical stability of the particles.

\section{Experimental}

\subsection{Oxygen carrier}

The Cu-based oxygen carrier used in this work was manufactured by Johnson Matthey using the incipient wet impregnation technique following industrially-relevant protocols. This

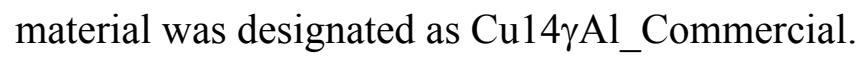


Table 1 shows the main physicochemical properties corresponding to the fresh particles of

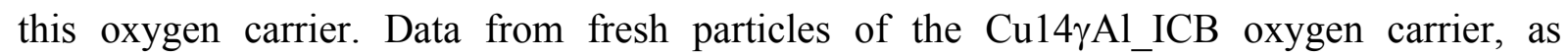
benchmark material, are included for comparison purposes.

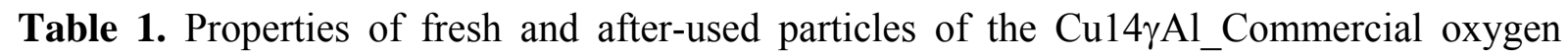

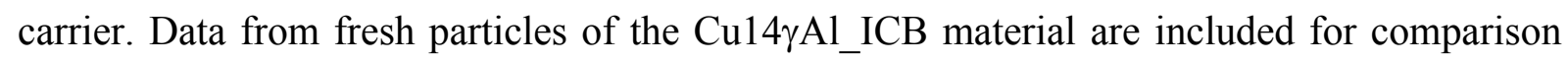
purposes.

\begin{tabular}{|c|c|c|c|c|}
\hline \multirow[t]{2}{*}{ Oxygen carrier } & \multicolumn{3}{|c|}{ 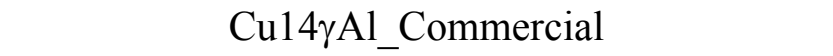 } & \multirow{2}{*}{ 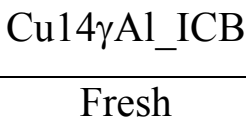 } \\
\hline & Fresh & Used & Used & \\
\hline & & $60 \mathrm{~h}$ & $65 \mathrm{~h}$ & \\
\hline & & $\mathrm{T}=800^{\circ} \mathrm{C}$ & $\mathrm{T}=900^{\circ} \mathrm{C}$ & \\
\hline Total $\mathrm{CuO}$ content $(\mathrm{wt} . \%)^{\mathrm{a}}$ & 13.8 & 10.1 & 10.0 & 14.2 \\
\hline $\mathrm{d}_{\mathrm{p}}(\mu \mathrm{m})$ & 153 & 151 & 139 & 225 \\
\hline Porosity $(\%)$ & 53.0 & 49.1 & 48.7 & 54.8 \\
\hline Mechanical strength $(\mathrm{N})$ & 1.2 & 1.2 & 0.7 & 2.9 \\
\hline AJI (\%) & 3.1 & 2.6 & 46.4 & 4.3 \\
\hline \multirow{4}{*}{ XRD phases } & $\mathrm{CuO} \mathrm{CuAl}{ }_{2} \mathrm{O}_{4}$ & $\mathrm{CuO}, \mathrm{CuAl}_{2} \mathrm{O}_{4}$ & $\mathrm{CuO}, \mathrm{CuAl}_{2} \mathrm{O}_{4}$ & $\mathrm{CuO} \mathrm{CuAl}{ }_{2} \mathrm{O}_{4}$ \\
\hline & $\delta-\mathrm{Al}_{2} \mathrm{O}_{3}$ & $\mathrm{CuAlO}_{2}$ & $\alpha-\mathrm{Al}_{2} \mathrm{O}_{3}$ & $\delta-\mathrm{Al}_{2} \mathrm{O}_{3}$ \\
\hline & & $\delta-\mathrm{Al}_{2} \mathrm{O}_{3}$ & & \\
\hline & & $\alpha-\mathrm{Al}_{2} \mathrm{O}_{3}$ & & \\
\hline
\end{tabular}

${ }^{\text {a }}$ determined by ICP-AES

\subsection{Oxygen carrier characterization techniques}

Both fresh and used oxygen carrier particles were physically and chemically characterized using different techniques with the aim of analysing the changes undergone by the Cu14 $\gamma$ Al_Commercial material throughout the time of operation in the continuous CLC unit.

The reactivity and the active $\mathrm{CuO}$ content were determined by TGA, CI Electronics type, 
described elsewhere, ${ }^{38}$ whereas the total $\mathrm{CuO}$ content in the fresh and used samples was determined by inductively coupled plasma atomic emission spectroscopy (ICP-AES) with a Jobin Ybon 2000 spectrometer.

The particle size distribution of the oxygen carrier material was measured with a laser diffraction technique according to ISO 13320 Standard with a LS 13320 Beckham Coulter equipment. The porosity and pore size distribution were calculated by $\mathrm{Hg}$ intrusion in a Quantachrome PoreMaster apparatus. The force needed to fracture a particle was measured with a Shimpo FGN-5X dynamometer. The crushing strength value was taken from, at least, 20 measurements. The attrition resistance was determined using a three-hole air jet attrition tester ATTRI-AS (Ma.Tec. Materials Technologies Snc) configured according to the ASTMD-5757 standard. As specified in the ASTM method, $50 \mathrm{~g}$ of material were tested under an air flow of $10 \mathrm{~L} \mathrm{~min}^{-1}$, which supposes a jet speed of $490 \mathrm{~m} \mathrm{~s}^{-1}$. The weight loss of fines was recorded after $1 \mathrm{~h}$ and $5 \mathrm{~h}$ of operation, respectively. The percentage of fines after a $5 \mathrm{~h}$ test is defined as the Air Jet Index (AJI). According to the ASTM method, particles with a size lower than $20 \mu \mathrm{m}$ are considered as fines. AJI values were determined by duplicate both for fresh and used samples subjected to redox cycles at high temperature in the continuous CLC unit. The reducibility of the Cu14 $\gamma \mathrm{Al}$ _Commercial samples was determined by temperature programmed reduction (TPR) experiments in a flow apparatus AUTOCHEM II from Micromeritics. Prior to the TPR experiment, the sample was flushed with Ar during 1 hour. After this pre-treatment, samples were heated at $7{ }^{\circ} \mathrm{C} \min ^{-1}$ from room temperature to $1100{ }^{\circ} \mathrm{C}$ with a flow of $20 \mathrm{~mL} \mathrm{~min}^{-1}$ of a mixture 10 vol. $\% \mathrm{H}_{2} / 90$ vol.\% Ar. XRD diffractograms were collected by a Bruker D8 Advance X-ray powder diffractometer equipped with an X-ray source with a $\mathrm{Cu}$ anode working at $40 \mathrm{kV}$ and $40 \mathrm{~mA}$ and an energy-dispersive onedimensional detector. The diffraction pattern was obtained over the $2 \theta$ range of $10^{\circ}$ to $80^{\circ}$ with a step of $0.019^{\circ}$. The assignation of crystalline phases was performed according to Joint 
Committee on Powder Diffraction Standards. Quantitative XRD analysis was performed by Rietveld refinement using TOPAS software to obtain the amorphous phase content of the oxygen carrier particles. Finally, the microstructure of the oxygen carrier particles was studied by means of a scanning electron microscopy (SEM) system (Model ISI DS-30). This equipment was coupled to an ultrathin window PGT Prism detector for energy-dispersive Xray (EDX) to perform elemental microanalyses.

\section{$2.3500 \mathrm{~W}_{\text {th }}$ continuous CLC unit}

The performance of the $\mathrm{Cu} 14 \gamma \mathrm{Al} \_\mathrm{Commercial}$ material for the combustion of $\mathrm{CH}_{4}$ as fuel was evaluated in a $500 \mathrm{~W}_{\text {th }}$ CLC pilot plant designed and built at the Instituto de Carboquímica (ICB-CSIC). A schematic diagram of the aforementioned CLC pilot plant is shown in Fig. 2.

The continuous CLC unit consists of two bubbling fluidized bed reactors, the fuel reactor and the air reactor, interconnected by a loop seal, a riser for solids transport, a solids valve to control the solids circulation rate between both reactors, a cyclone, a diverting solids valve to take samples from the air reactor, a small deposit to take samples from the fuel reactor and two filters to collect the elutriated fines during the process. This facility also has on-line gas analysers to get continuous data of gas composition at the fuel reactor and air reactor outlet streams. A more detailed description of the $500 \mathrm{~W}_{\text {th }}$ continuous CLC system can be found elsewhere. $^{21}$ 


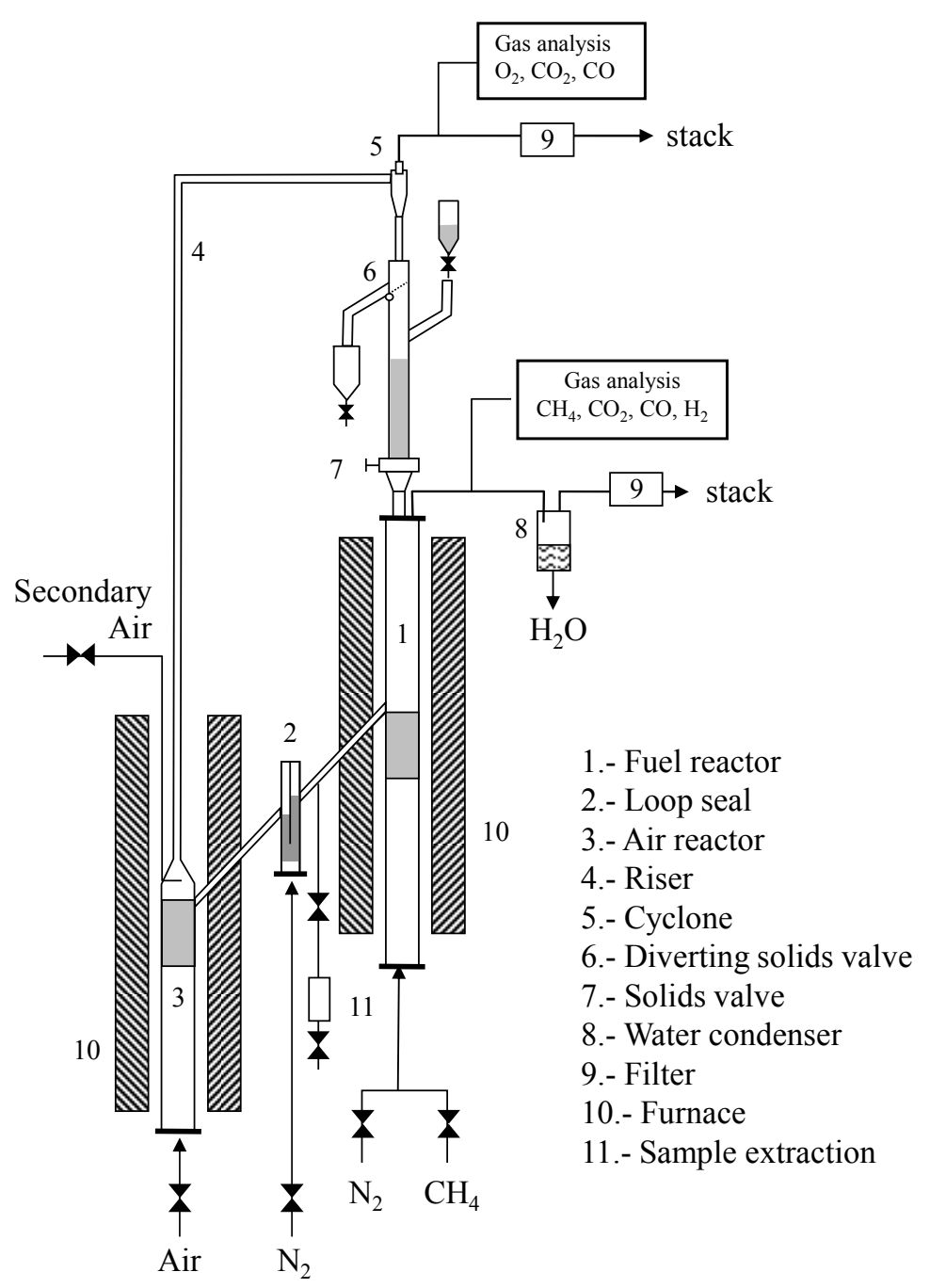

Fig. 2. Schematic diagram of the $500 \mathrm{~W}_{\text {th }}$ continuous CLC system (ICB-CSIC-g1 facility).

\subsection{Testing conditions}

Two experimental campaigns were performed in the CLC facility with the Cu14 $\gamma$ Al_Commercial oxygen carrier. The total solids inventory used in the system for both test series was $1.2 \mathrm{~kg}$, of which 0.3 and $0.4 \mathrm{~kg}$ were in the fuel and air reactors, respectively. The first experimental campaign consisted of 60 hours of continuous operation working at a temperature of $800{ }^{\circ} \mathrm{C}$ both in the reduction and oxidation reactor. The second one was conducted at a temperature of $900{ }^{\circ} \mathrm{C}$ in both reactors and lasted for 65 hours. A new batch of fresh particles was used in each of these test series. 
The inlet gas flows fed to the fuel reactor, loop seal and air reactor were maintained constant for all the tests. The gas flow fed to the fuel reactor was $170 \mathrm{LN} \mathrm{h}^{-1}$, which corresponded to an inlet gas velocity of $0.1 \mathrm{~m} \mathrm{~s}^{-1}$. The bottom loop seal was fluidized with $\mathrm{N}_{2}\left(45 \mathrm{LN} \mathrm{h}^{-1}\right)$. The air flow fed to the air reactor was divided into the primary air $\left(720 \mathrm{LN} \mathrm{h}^{-1}\right)$, added at the bottom bed, and the secondary air $\left(150 \mathrm{LN} \mathrm{h}^{-1}\right)$, added at the top of the bubbling bed to help particle entrainment in the riser.

A mixture of $\mathrm{CH}_{4}$ and $\mathrm{N}_{2}$ was used as fuel to analyse the behaviour of the Cu14 $\gamma$ Al_Commercial material for the CLC process. $\mathrm{N}_{2}$ acted as diluting agent. The main operating conditions and data corresponding to the tests performed in the $500 \mathrm{~W}_{\text {th }}$ continuous CLC system are shown in Table 2.

Table 2. Main operating conditions corresponding to the tests carried out in the $500 \mathrm{~W}_{\text {th }}$

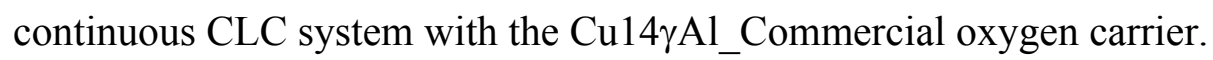

\begin{tabular}{llllllll}
\hline Test & $\mathrm{CH}_{4}$ & $\mathrm{~T}_{\mathrm{FR}}$ & $\begin{array}{l}\mathrm{T}_{\mathrm{AR}} \\
(\mathrm{vol} . \%)\end{array}$ & $\begin{array}{l}\left.\mathrm{f}_{\mathrm{s}} \mathrm{C}\right) \\
\left({ }^{\circ} \mathrm{C}\right)\end{array}$ & $\begin{array}{l}\phi \\
(\mathrm{kg} / \mathrm{h})\end{array}$ & $\begin{array}{l}\text { Power } \\
\left(\mathrm{W}_{\text {th }}\right)\end{array}$ & $\begin{array}{l}\text { Solids inventory } \\
(\mathrm{kg} / \mathrm{MW})\end{array}$ \\
\hline $\mathrm{T} 1$ & 20 & 800 & 800 & 14.3 & 2.6 & 338 & 888 \\
$\mathrm{~T} 2$ & 25 & 800 & 800 & 14.4 & 2.1 & 423 & 709 \\
$\mathrm{~T} 3$ & 30 & 800 & 800 & 13.6 & 1.6 & 508 & 590 \\
$\mathrm{~T} 4$ & 40 & 800 & 800 & 13.1 & 1.2 & 677 & 443 \\
$\mathrm{~T} 5$ & 20 & 900 & 900 & 11.0 & 2.0 & 338 & 888 \\
$\mathrm{~T} 6$ & 25 & 900 & 900 & 11.0 & 1.6 & 423 & 709 \\
$\mathrm{~T} 7$ & 30 & 900 & 900 & 11.0 & 1.3 & 508 & 590 \\
$\mathrm{~T} 8$ & 40 & 900 & 900 & 11.0 & 1.0 & 677 & 443 \\
\hline
\end{tabular}

The oxygen carrier-to-fuel ratio, $\phi$, which is defined as the ratio between the flow of oxygen supplied by the oxygen carrier and the oxygen needed to stoichiometrically react with the fuel 
flow, is calculated by Equation 1 as follows:

$\phi=\frac{F_{C u}}{4 \cdot F_{\mathrm{CH}_{4}}}$

where $\mathrm{F}_{\mathrm{Cu}}$ is the molar flow rate of copper present in the oxygen carrier in any form, i.e., $\mathrm{CuO}, \mathrm{Cu}_{2} \mathrm{O}, \mathrm{Cu}, \mathrm{CuAl}_{2} \mathrm{O}_{4}$ and $\mathrm{CuAlO}_{2}$, calculated from the corresponding solids circulation rate in the $\mathrm{CLC}$ unit, $\mathrm{f}_{\mathrm{s}}$, and $\mathrm{F}_{\mathrm{CH} 4}$ is the inlet molar flow rate of $\mathrm{CH}_{4}$ in the fuel reactor.

In both test series, conducted at $800{ }^{\circ} \mathrm{C}(\mathrm{T} 1-\mathrm{T} 4)$ and $900{ }^{\circ} \mathrm{C}(\mathrm{T} 5-\mathrm{T} 8)$ respectively, the effect of the oxygen carrier-to-fuel ratio, $\phi$, on the combustion efficiency was evaluated varying the concentration of $\mathrm{CH}_{4}$ in the gaseous stream fed to the fuel reactor from 20 to 40 vol. \%, whereas the solids circulation rate, fs, was maintained approximately constant. The range of $\mathrm{CH}_{4}$ concentration values used in this work corresponds to an input thermal power between 338 and $667 \mathrm{~W}$.

The combustion efficiency, $\eta_{c}$, is defined as the ratio of oxygen consumed by the gas leaving the fuel reactor to that consumed by the gas when the fuel is completely burnt to $\mathrm{CO}_{2}$ and $\mathrm{H}_{2} \mathrm{O}$. This parameter can be expressed as follows:

$\eta_{c}=1-\frac{\left(x_{C O}+x_{\mathrm{H}_{2}}+4 \cdot x_{\mathrm{CH}_{4}}\right)_{\text {out }} \cdot F_{\text {out }}}{\left(4 \cdot x_{\mathrm{CH}_{4}}\right)_{\text {in }} \cdot F_{\text {in }}}$

where $F_{\text {in }}$ and $F_{\text {out }}$ are the molar flows at the inlet and outlet of the fuel reactor, respectively, and $x_{i}$ is the molar fraction of the gas $i$. A value of parameter $\eta_{c}$ close to 1 indicates that almost full combustion conditions have been achieved in the CLC unit.

\section{Results and discussion}

\subsection{Oxygen carrier performance during $\mathrm{CH}_{4}$ combustion in CLC}

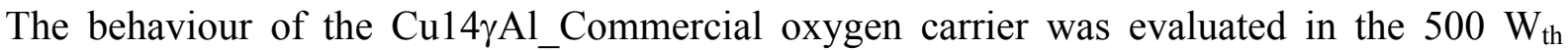


continuous CLC system with the aim of determining if this material was a good candidate to upscale CLC technology for gaseous fuels. In a first step, 60 hours of continuous operation were conducted at $800{ }^{\circ} \mathrm{C}$, both in the fuel and air reactors, to analyse the combustion efficiency and the particle integrity of the selected material. Fig. 3 (a) shows the combustion efficiency of this $\mathrm{Cu}$-based oxygen carrier as a function of the oxygen carrier-to-fuel ratio, $\phi$, used in the CLC unit. This material presented a good behaviour obtaining complete $\mathrm{CH}_{4}$ combustion at $\phi$ values around $1.5-2.0$. The corresponding solids inventories used in these tests are shown in Table 2 . However, it was previously determined that the oxygen carrier-tofuel ratio $(\phi)$ had more influence on the combustion efficiency $\left(\eta_{c}\right)$ than the solids inventory. In addition, complete combustion could be obtained with lower solids inventory values. ${ }^{39}$

In a second step, a new batch of this material was used to analyse its performance at a higher temperature, i.e., $900{ }^{\circ} \mathrm{C}$. As a whole, 65 hours of continuous operation were conducted at these conditions without operational problems, such as agglomeration or defluidization. Fig. 3 (b) shows the effect of the oxygen carrier-to-fuel ratio $(\phi)$ on the combustion efficiency $\left(\eta_{c}\right)$ at high temperature. The results were excellent, even better than the ones obtained at $800{ }^{\circ} \mathrm{C}$, since higher combustion efficiencies were achieved at low $\phi$ values, which indicated that an increase of the operating temperature in the CLC unit was clearly beneficial. The performance

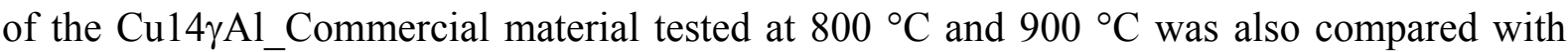
the one presented by the reference material at these conditions and the results were very similar. $^{22,33}$

An adequate oxygen carrier to upscale CLC technology must present not only a good behaviour for fuel combustion, but also a high particle lifetime. The particle lifetime of an oxygen carrier can be experimentally determined in a CLC unit based on its corresponding attrition rate. The experimental attrition rate as a function of the operation time was 
determined by collecting and weighing the particles elutriated from the reactors. The particles collected in the filters with a size higher than $45 \mu \mathrm{m}$ were returned to the system. Thus, attrition rate, $\mathrm{A}\left(\% \mathrm{~h}^{-1}\right)$, is defined through the following equation:

$A=\frac{m_{f}}{m_{t} \cdot \Delta t} \cdot 3600 \cdot 100$

where $\mathrm{m}_{\mathrm{f}}$ is the mass of elutriated particles with a particle size lower than $45 \mu \mathrm{m}$ during a particular period of time, $\Delta \mathrm{t}$ (expressed in seconds), and $\mathrm{m}_{\mathrm{t}}$ is the total mass of solids in the CLC plant.

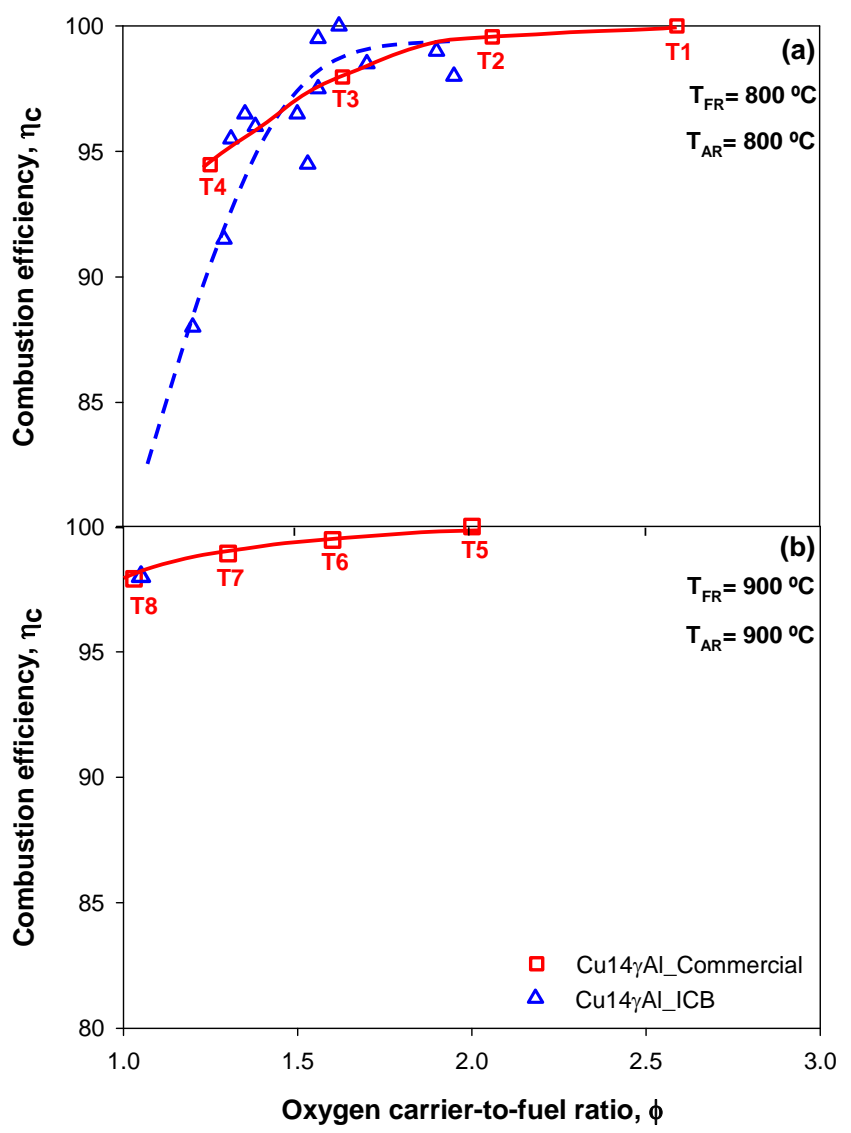

Fig. 3. Effect of the oxygen carrier-to-fuel ratio on the combustion efficiency with the Cu14 $\gamma \mathrm{Al}$ _Commercial oxygen carrier. (a) $\mathrm{T}_{\mathrm{FR}}=800{ }^{\circ} \mathrm{C}, \mathrm{T}_{\mathrm{AR}}=800{ }^{\circ} \mathrm{C}$, (b) $\mathrm{T}_{\mathrm{FR}}=900{ }^{\circ} \mathrm{C}, \mathrm{T}_{\mathrm{AR}}=$ $900{ }^{\circ} \mathrm{C} . \mathrm{Cu} 14 \gamma \mathrm{Al}$ ICB oxygen carrier is taken as reference material. ${ }^{22,33}$ 


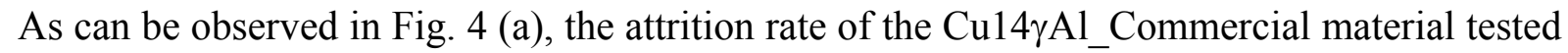
at $800{ }^{\circ} \mathrm{C}$ was high $\left(\sim 0.25 \% \mathrm{~h}^{-1}\right)$ during the first hours of operation due to rounding effects in the oxygen carrier particles, but it progressively decreased until a constant value was reached. Thus, the attrition rate was quickly stabilized at $0.02 \% \mathrm{~h}^{-1}$.

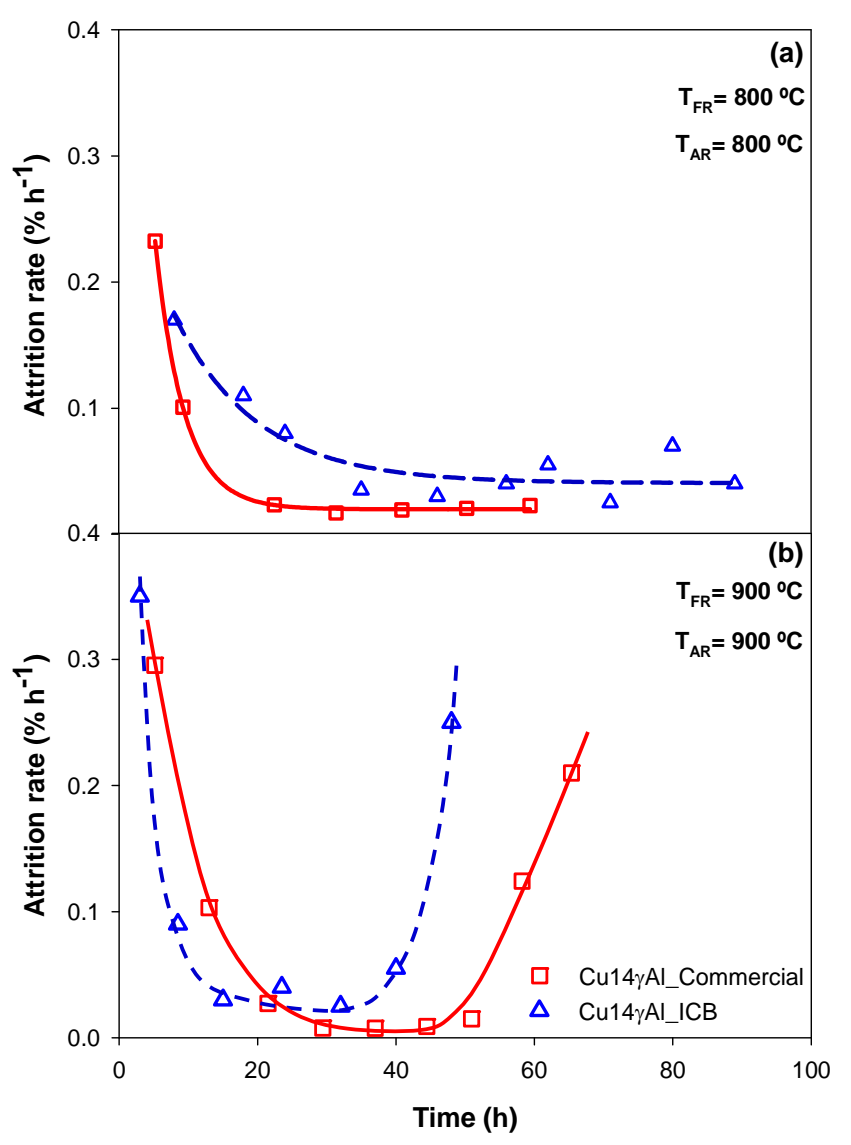

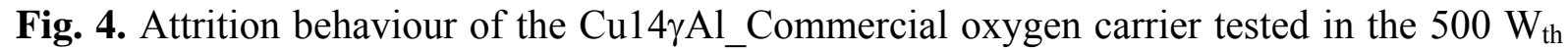

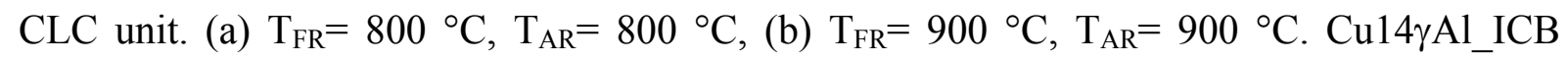
oxygen carrier is taken as reference material. ${ }^{22,33}$

This stabilized value is taken to estimate the corresponding value of particle lifetime. The particle lifetime of an oxygen carrier, LT (h), can be estimated from the attrition rate through Equation 4: 
$L T(h)=\frac{100}{A}$

This attrition rate value implied an estimated particle lifetime of 5000 hours, which was two times higher than the particle lifetime inferred for the reference material. ${ }^{22}$

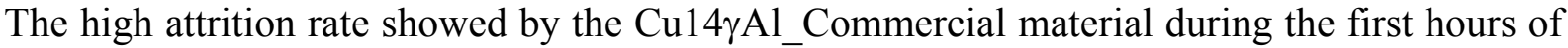
operation caused a significant copper loss in the oxygen carrier particles, as can be clearly observed in Fig. 5. However, the total copper oxide content was rapidly stabilized at 10.1 wt.\% throughout the time of operation. The active copper oxide content present in the oxygen carrier particles was also determined by TGA.

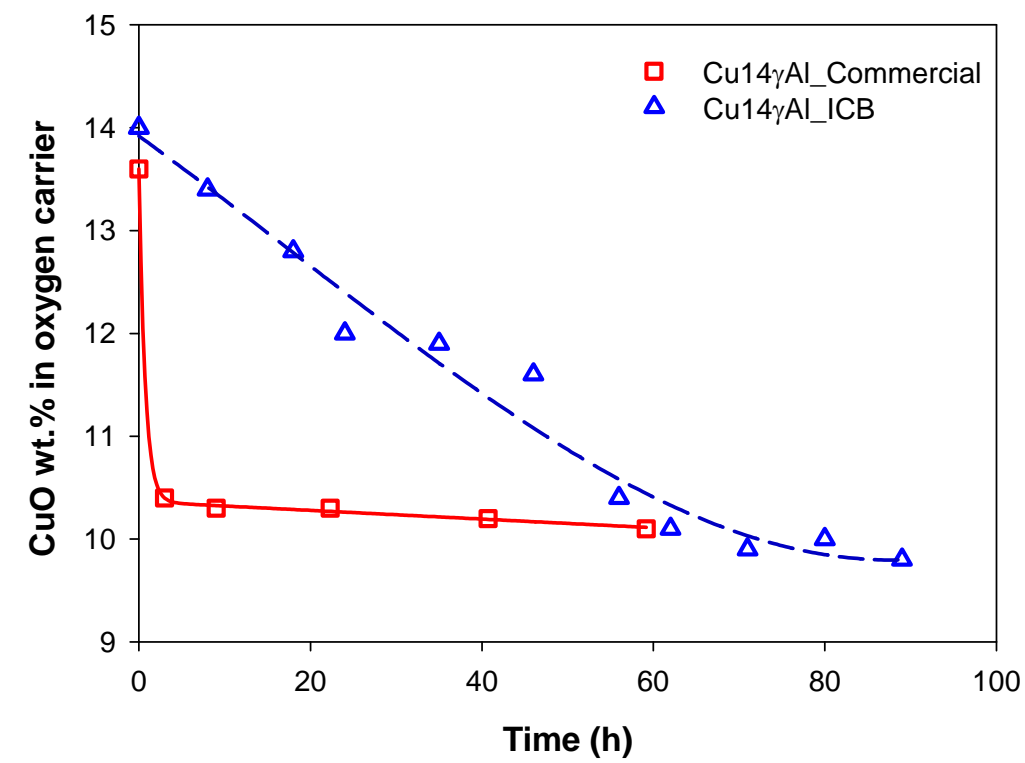

Fig. 5. Total copper oxide content versus time of operation for the Cu14yAl_Commercial oxygen carrier tested in the $500 \mathrm{~W}_{\text {th }}$ continuous CLC system at $800^{\circ} \mathrm{C}$. Cu14 $\gamma \mathrm{Al}$ ICB oxygen carrier is taken as reference material. ${ }^{30}$

The copper oxide content values calculated from TGA technique were almost identical to the total content values, indicating that the remaining copper oxide could be reduced with the 
gaseous fuels. In this point, it must be highlighted that the remaining metal oxide content was high enough to obtain very satisfactory results in terms of combustion efficiency, as was shown in Fig. 3. Comparing this total copper oxide content profile with the one obtained for

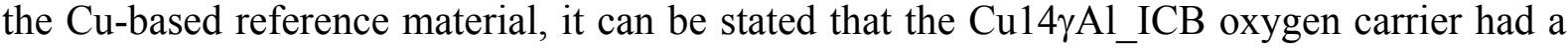
smoother but similar copper loss.

The attrition rate was also experimentally determined in the continuous $\mathrm{CLC}$ unit at $900{ }^{\circ} \mathrm{C}$ to evaluate if an increase of the temperature affected on the mechanical integrity of the Cu14yAl_Commercial material. The attrition rate profile showed in Fig. 4 (b) confirmed that the increase of the temperature in the fuel and air reactors was clearly detrimental for the performance of this oxygen carrier. Initially, the attrition rate followed a similar tendency to the one found for the same material operating at $800{ }^{\circ} \mathrm{C}$, i.e., the amount of elutriated fines collected in the filters of the CLC unit was very high during the first hours of operation but it was rapidly stabilized at a very low value $\left(<0.02 \% \mathrm{~h}^{-1}\right)$. However, the attrition rate started to increase in a great extent after 45-50 hours of operation. Finally, after 65 hours, it was decided to stop the experimentation. At that moment, the attrition rate reached a value of $0.22 \% \mathrm{~h}^{-1}$, which indicated that the corresponding particle lifetime of this oxygen carrier was lower than

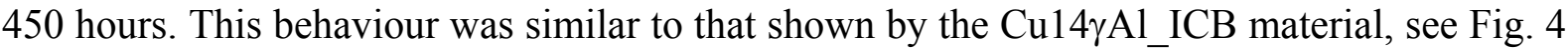
(b).

Based on the previous results achieved with the Cu14yAl Commercial oxygen carrier regarding combustion efficiency and attrition resistance, it can be stated that it presented an excellent performance for the CLC process at $800{ }^{\circ} \mathrm{C}$, even better than the reference material. On the other hand, when the CLC unit was operated at $900{ }^{\circ} \mathrm{C}$, the oxygen carrier exhibited an excellent behaviour for $\mathrm{CH}_{4}$ combustion, but an inadequate mechanical integrity.

\subsection{Oxygen carrier characterization}




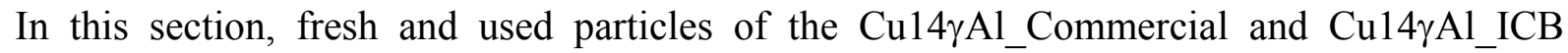
oxygen carriers were analysed by means of different characterization techniques to understand why the former exhibited better properties for the CLC process than the latter considering that the amount of metal oxide, the type of support $\left(\gamma-\mathrm{Al}_{2} \mathrm{O}_{3}\right)$, and the preparation method were similar for both materials.

\subsubsection{Reactivity of the oxygen carrier}

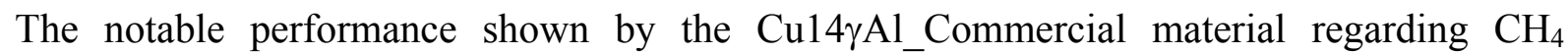
combustion efficiency can be explained based on both the ability of copper oxide to completely burn the fuel to $\mathrm{CO}_{2}$ and $\mathrm{H}_{2} \mathrm{O}$ and the high reaction rate exhibited by the oxygen carrier particles.

Fig. 6 illustrates the reduction conversion $\left(\mathrm{X}_{\mathrm{r}}\right)$ versus time curves both for fresh and used particles extracted from the air reactor of the CLC pilot plant at different times of operation during the combustion tests performed at $800^{\circ} \mathrm{C}$. The data correspond to the third reduction cycle obtained in the TGA equipment. Fresh sample exhibited a high reduction rate reaching an $80 \%$ of the reduction conversion in less than 10 seconds. As can be observed, the reaction rate barely changed throughout the 60 hours of continuous operation. 


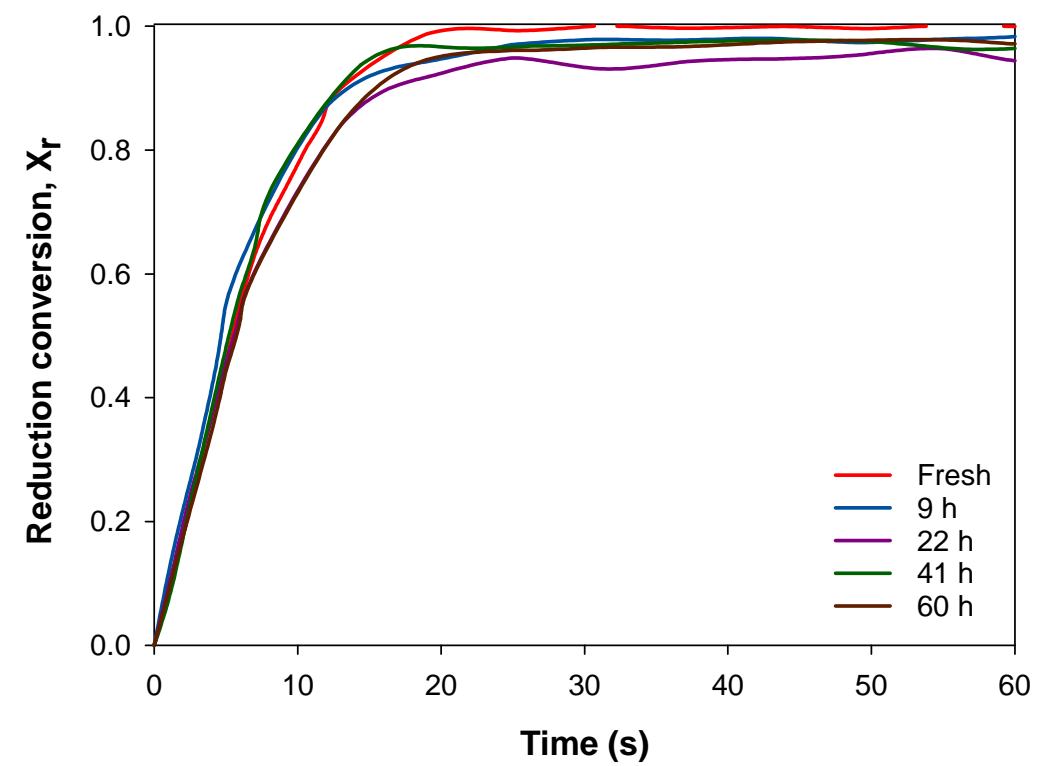

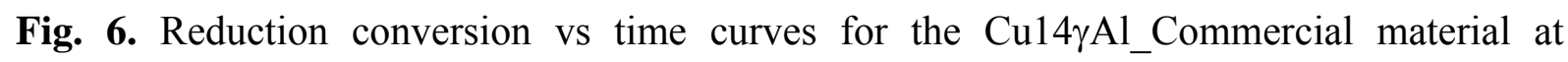
different times of operation in the CLC unit $(0,9,22,41$ and $60 \mathrm{~h})$ during the combustion tests performed at $800{ }^{\circ} \mathrm{C}$. Reducing agent: 15 vol. $\% \mathrm{H}_{2}\left(\mathrm{~N}_{2}\right.$ to balance $) . \mathrm{T}=800{ }^{\circ} \mathrm{C}$.

\subsubsection{Air Jet Index (AJI)}

The evolution of the attrition resistance of the oxygen carrier particles during the $\mathrm{CH}_{4}$ combustion tests was also analysed by means of the determination of the Air Jet Index (AJI). Samples were extracted from the CLC pilot plant at different times of operation during the experimental campaigns conducted at $800{ }^{\circ} \mathrm{C}$ and $900{ }^{\circ} \mathrm{C}$. The remarkable result regarding attrition rate obtained with the Cu14yAl_Commercial at $800{ }^{\circ} \mathrm{C}$, see Fig. 4 (a), was also corroborated by means of the attrition resistance tests performed to fresh and used particles according to the ASTM-D-5757 standard. The AJI for the fresh oxygen carrier particles was $3.1 \%$, which is a noteworthy value taking into account that materials with an AJI of $5 \%$ or below are considered appropriate for their use as oxygen carrier in a CLC process, according to the selection criteria given in the work of Cabello et al. ${ }^{9}$ 


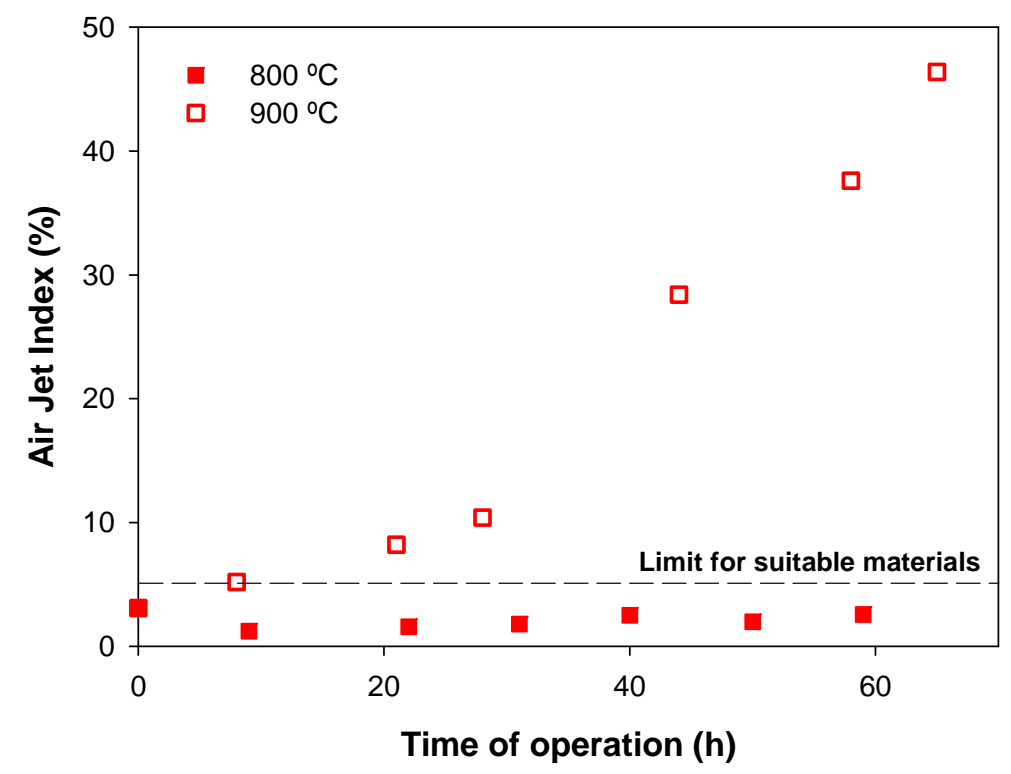

Fig. 7. Evolution of the Air Jet Index (AJI) throughout the time of operation in the continuous

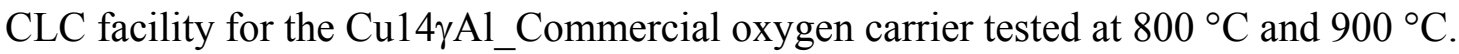

In addition, this low value was maintained throughout the time of operation in the continuous CLC unit, see Fig. 7. In this regard, the AJI took a value of $2.6 \%$ for the oxygen carrier particles extracted from the air reactor of the CLC facility at the end of the experimental campaign.

The fact that this parameter was maintained at a very low and almost constant value suggested that the thermal and chemical stresses suffered by the particles during operation in the CLC process did not affect their attrition behaviour. Moreover, if other physical properties of the oxygen carrier particles, such as density, crushing strength and particle size distribution (PSD), are also maintained roughly constant along the time of operation, there is a high degree of confidence that the oxygen carrier particles will preserve an adequate mechanical integrity during a period of time corresponding to the particle lifetime predicted by the attrition rate experimentally determined. ${ }^{9}$ In this case, the values of density, porosity and PSD 
corresponding to the oxygen carrier particles extracted from the CLC unit after 60 hours of operation barely changed with respect to the ones showed by fresh material, see data from Table 1 and Fig. 8, respectively.

Unlike tests performed at $800{ }^{\circ} \mathrm{C}$, in which the AJI remained approximately constant over time, the fact of operating at higher temperature produced a steady increase in this parameter reaching a value of $46.4 \%$ after 65 hours of operation, see Fig. 7. This result is shown in accordance with the inadequate attrition value measured in the pilot plant experimentally. In this case, the mechanical resistance was highly deteriorated due to the considerable increase of the thermal and chemical stresses underwent by the particles of this $\mathrm{Cu}$-based oxygen carrier. This deterioration was also reflected in a decrease of both the crushing strength and

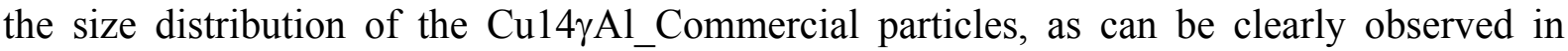
Table 2 and Fig. 8.

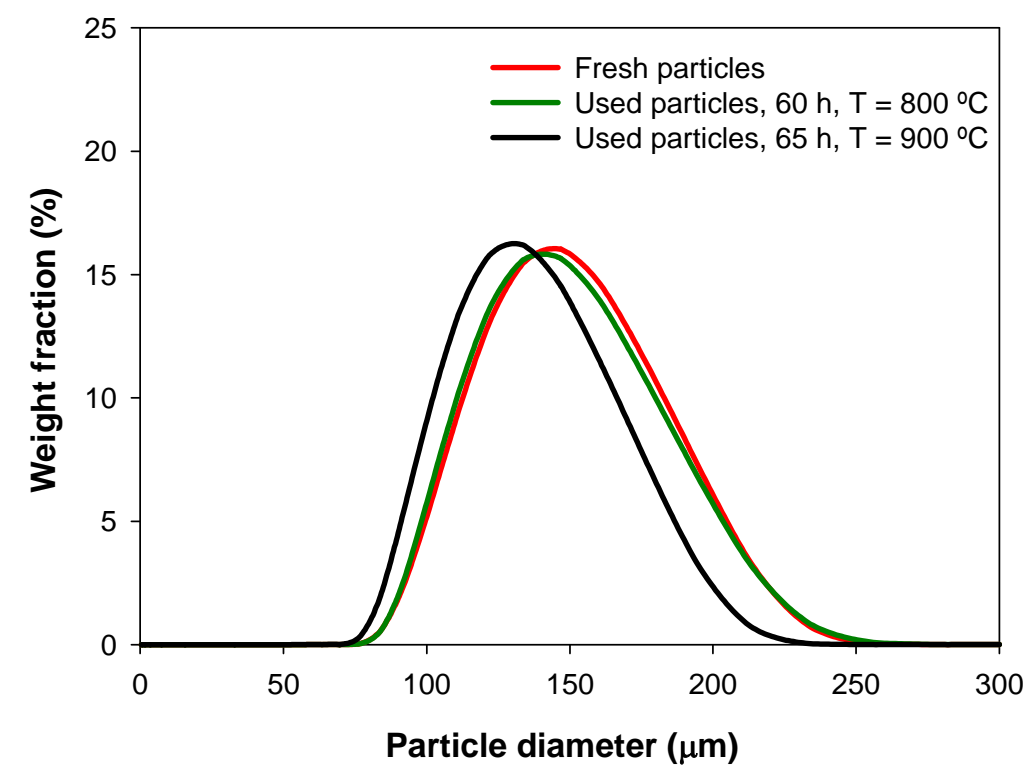

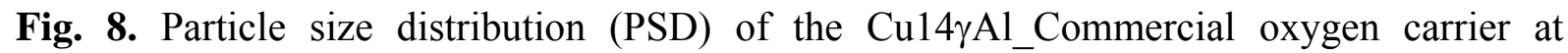
different times of operation and testing conditions. 


\subsubsection{XRD analyses}

Fig. 9 shows the XRD patterns corresponding to fresh and used samples of Cu14 $\gamma$ Al_Commercial and Cu14 $\gamma$ Al_ICB oxygen carriers as well as the assignation of phases present in each sample. Used samples refer to oxygen carrier particles extracted from the air reactor at the end of the corresponding experimental campaigns performed at $800{ }^{\circ} \mathrm{C}$ and $900{ }^{\circ} \mathrm{C}$. Quantitative analyses of the $\mathrm{Cu}$-based phases, as well as the amorphous phase content in the samples, have been also determined from Rietveld refinement. Regarding the fresh materials, it was concluded that the amount of free $\mathrm{CuO}$ was higher in the

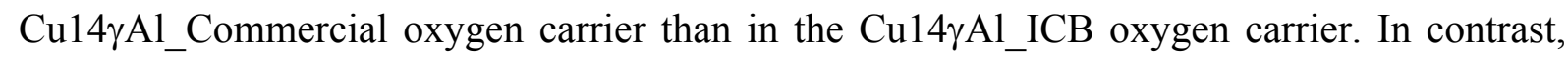
fresh particles of the reference material presented a higher amount of $\mathrm{CuAl}_{2} \mathrm{O}_{4}$. Previous research works performed at ICB-CSIC demonstrated that both $\mathrm{CuO}$ and $\mathrm{CuAl}_{2} \mathrm{O}_{4}$ could be considered as active copper-based species for CLC process since they were able to react with different gaseous fuels. ${ }^{19,20,30}$ 


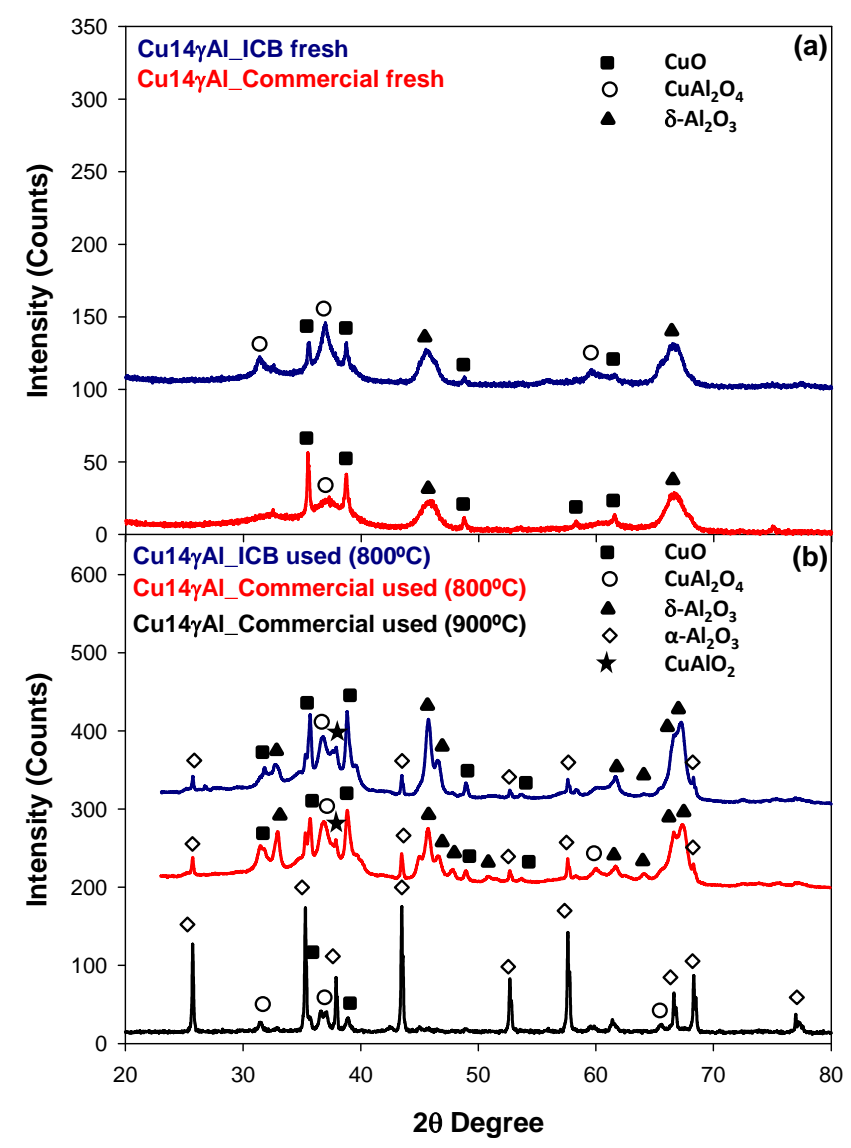

Fig. 9 XRD patterns of (a) fresh and (b) used particles of the Cu14 $\gamma \mathrm{Al}$ Commercial and Cu14 $\gamma \mathrm{Al} \_$ICB oxygen carriers tested at $800{ }^{\circ} \mathrm{C}$ and $900{ }^{\circ} \mathrm{C}$.

In both materials, $\delta-\mathrm{Al}_{2} \mathrm{O}_{3}$ was detected as support. This fact implies that the support used to prepare both oxygen carriers, i.e., $\gamma-\mathrm{Al}_{2} \mathrm{O}_{3}$, underwent a phase change during the calcination process. Finally, the quantitative XRD analyses also concluded that the amorphous phase content in the Cu14yAl_Commercial particles was higher than in the particles of the benchmark material (37 wt.\% vs 32 wt.\%), see Table 3. The amorphous phase content was reduced in the used oxygen carrier particles of both materials due to the high temperature operation in the CLC units. This reduction degree was much more pronounced on the Cu14 $\gamma$ Al_Commercial particles tested at $900{ }^{\circ} \mathrm{C}$. In this point, it should be mentioned that the 
amorphousness decrease was mainly produced during the first 10 hours of continuous operation in the CLC units.

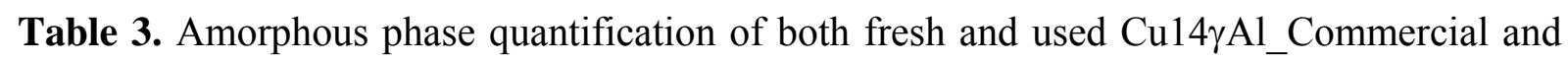
$\mathrm{Cu} 14 \gamma \mathrm{Al}$ ICB oxygen carrier particles and the corresponding support materials obtained from XRD data.

\begin{tabular}{|c|c|c|c|c|}
\hline & 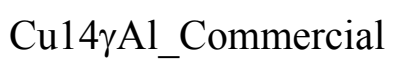 & 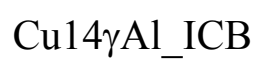 & $\gamma \mathrm{Al} \_$Commercial & $\gamma \mathrm{Al} \_\mathrm{ICB}$ \\
\hline Fresh & 37.0 & 32.0 & $37.8^{\mathrm{a}}$ & $33.8^{\mathrm{a}}$ \\
\hline Used $\left(800^{\circ} \mathrm{C}\right)$ & 33.0 & 26.0 & $36.4^{\mathrm{b}}$ & $32.3^{b}$ \\
\hline Used $\left(900^{\circ} \mathrm{C}\right)$ & 12.0 & & & \\
\hline
\end{tabular}

a) $1 \mathrm{~h}, 850{ }^{\circ} \mathrm{C}$ in furnace; b) $24 \mathrm{~h}, 800{ }^{\circ} \mathrm{C}$ in furnace.

In order to find the source of the varying degree of amorphousness of these oxygen carriers, XRD analyses were carried out to the corresponding alumina-based materials used as supports. These supports were calcined at two different conditions. On the one hand, the supports were calcined 1 hour at $850{ }^{\circ} \mathrm{C}$, being this heat treatment the one used during the preparation process of the fresh oxygen carriers. On the other hand, the supports were calcined 24 hours at $800^{\circ} \mathrm{C}$, thus simulating a long-term operation in a continuous CLC plant. The obtained results are also shown in Table 3. At both calcination conditions, the degree of amorphousness was higher in the alumina from which the Cu14 $\gamma \mathrm{Al}$ _Commercial material was developed than in the alumina from which the reference material was prepared. This result indicated that the amorphousness of the oxygen carrier was mainly provided by the aluminabased material used as support. Therefore, it can be concluded that a higher degree of amorphousness in the support of a $\mathrm{Cu}$-based oxygen carrier prepared by means of the impregnation method produces a higher amount of free $\mathrm{CuO}$ in the oxygen carrier particles 
because the support presents a lower degree of interaction with the active metal oxide avoiding the formation of a relevant amount of $\mathrm{CuAl}_{2} \mathrm{O}_{4}$. This fact could be beneficial with respect to the mechanical resistance of the oxygen carrier considering that both $\mathrm{CuO}$ and $\mathrm{CuAl}_{2} \mathrm{O}_{4}$ are highly reactive compounds with gaseous fuels. Finally, it should be pointed out that the amorphousness decrease detected in the oxygen carriers is due to the presence of copper since, if there is no copper, the amorphousness of the support is maintained roughly constant over time.

\subsubsection{Temperature programmed analyses}

Temperature programmed reduction (TPR) analyses were performed to fresh and after-used

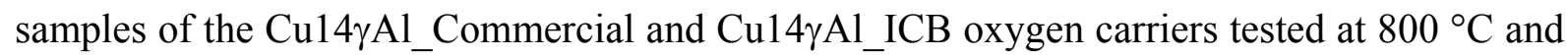
$900{ }^{\circ} \mathrm{C}$ to evaluate the reducibility of these materials, and, specifically, the interaction degree between the active metal oxide, i.e., $\mathrm{CuO}$, and the two different alumina-based materials used as supports.

Fig. 10 shows the TPR profiles of the analysed samples. Fresh and after-used oxygen carrier particles of both materials tested at $800{ }^{\circ} \mathrm{C}$ exhibited two reduction peaks at low temperature and a broad band at about $700{ }^{\circ} \mathrm{C}$. The peaks obtained at low temperature could be assigned to the reduction $\mathrm{CuO}-$ like species. These peaks have been also described as small $\mathrm{Cu}^{+2}$ domains and $\mathrm{CuO}$ clusters. ${ }^{40}$ The well resolved peaks in the TPR patterns of the samples seemed to indicate that these $\mathrm{CuO}$ species could be assigned to clusters and not to small $\mathrm{Cu}^{+2}$ domains. As can be observed in this Figure, mainly in the fresh samples, these low-temperature peaks

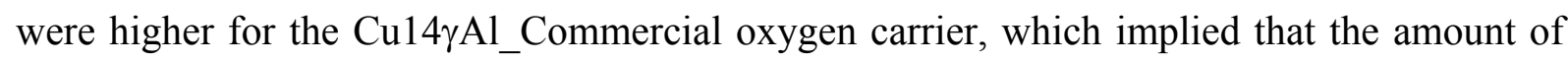
free $\mathrm{CuO}$ in the particles of this material was higher than in the particles of the reference material, which agrees with the XRD analyses. Moreover, the band found at $700{ }^{\circ} \mathrm{C}$ could be attributed to the reduction of $\mathrm{CuAl}_{2} \mathrm{O}_{4}$. In this case, this band was more noticeable in the TPR 
profiles corresponding to the $\mathrm{Cu} 14 \gamma \mathrm{Al} \_\mathrm{ICB}$ oxygen carrier which was also corroborated by the XRD results.

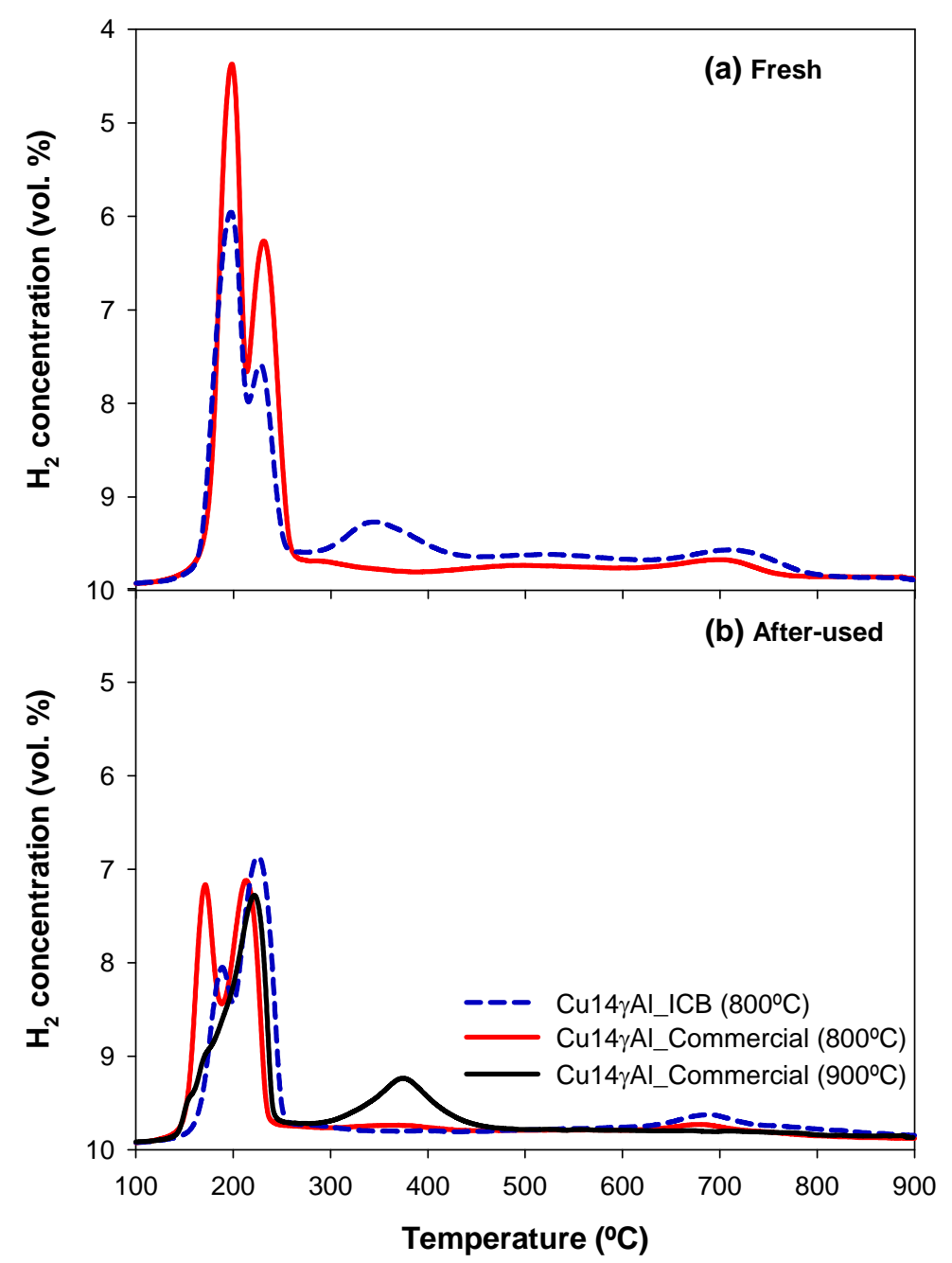

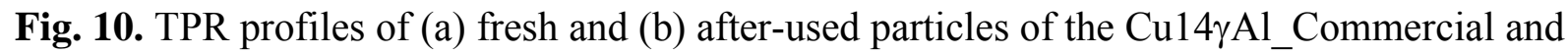

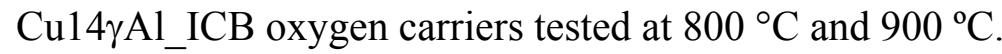

Moreover, it must be pointed out that the TPR profile corresponding to the fresh sample of the benchmark material showed a small band at about $350{ }^{\circ} \mathrm{C}$, which did not appear for the Cu14 $\gamma$ Al_Commercial oxygen carrier. The band observed at this temperature may indicate that $\mathrm{Cu}^{+2}$ was reduced to $\mathrm{Cu}^{+1}$ in the form of $\mathrm{CuAlO}_{2}$ due to the greater degree of interaction 